\title{
Los espacios de las ceremonias devocionales y litúrgicas de la monarquía trastámara*
}

\author{
José Manuel NieTo SoRIA \\ Universidad Complutense de Madrid \\ Departamento de Historia Medieval \\ jmniesor@ghis.ucm.es
}

\section{RESUMEN}

Según la experiencia de la dinastía Trastámara en Castilla, este trabajo estudia las ceremonias litúrgicas y religiosas más importantes de la monarquía, prestando atención a la utilización del espacio. Tres problemas son considerados: ¿cuáles fueron las principales ceremonias de la monarquía? ¿Cómo fueron utilizadas las capillas reales? ¿Cómo fueron utilizados los palacios reales? El resultado de este análisis es que estas ceremonias tuvieron lugar en catedrales y edificios religiosos.

Palabras clave:

Monarquía, Trastámara, Castilla, Ceremonia litúrgica, Catedral, Capilla Real, Palacio Real.

\section{Places for devotional and liturgical ceremonies of the Trastámara monarchy}

\begin{abstract}
According to the experience of the Trastámara dinasty in Castile, this work studies the most important liturgical and religious ceremonies of the Monarchy to pay attention to the use of space. Three issues are considered: what were the main liturgical ceremonies of the monarchy? How were the royal chapels used? How were the royal palaces used? The result of this analysis is that these ceremonies were held in cathedrals and religious buildings.
\end{abstract}

Key words: Monarchy, Trastámara, Castile, Liturgical Ceremony, Cathedral, Royal Chapel, Royal Palace.

* Este trabajo forma parte de los resultados del Proyecto de Investigación de la Secretaría de Estado de Investigación, Desarrollo e Innovación n n HAR2010-16762 "Prácticas de consenso y de pacto e instrumentos de representación en la cultura política castellana (siglos XIII al XV)". 
En un manuscrito de la British Library podemos leer en un texto autógrafo el testimonio que nos ofrece un comerciante castellano que, procedente de Flandes, marcha en peregrinación al monasterio de Guadalupe, adonde llega en la noche del sábado 7 de julio de $1505^{1}$. Al referirse a la que denomina la Capilla de Nuestra Señora, la señala como el centro principal del monasterio en cuanto a intensa actividad peregrinatoria, pues, según afirma, "nunca de noche nin de dya los postigos della se cyerran por el mucho pelegrinage que siempre ay y entrando dentro". En su descripción de esta capilla relata lo siguiente:

"Sobre la mano derecha está la capilla de Nuestra Señora, que es grande (...) con 15 gradas con que souben al santo altar en el qual desde las 4 de la mañana fasta las doze del día nunca falta misa y está a la mano derecha del altar el relicario, que es muy rico a maravilla, el qual tiene de altura estado e medio de ombre, labrado de mucho oro fino de muy ricas obras, en las quales puertas están entretaladas las armas del rey don Hanriche de Castilla de gloriosa memoria, e tienen por orlas todos los doze apóstoles, e enzima de las dichas puertas, la coronación de Nuestra Señora, delante del dicho relicario e lampadas grandes de plata que arden de noche y de día en el altar de Nuestra Señora están dos imágenes suyas de una baxo e otra ençima de pequeño bulto e la color baça, e ella mucho adornada de vestiduras e esta es la gloryosa que faze los infinitos miraglos de cada día, delante la qual arden todos los días e noches que nunca se matan XXVIII lampadas de plata de las grandes e de otras pequeñas a manera de naos en que ay en medio una lampada que dieron los señores de la mesta de los ganados, la qual es tan grande como una pequeña mesa redonda dorada y esmaltada, que puede pesar dozientos marcos de plata. A la mano derecha del altar está en alto tanto como tres estados de ombres en un arcón el entyerramiento del rey don Henrique, que Dios aya, el qual está fechado su bulto como sobre una cama, vestido de sus vestiduras reales con una corona de oro en su cabeça e un peto de oro / Fol. 55v (...) la obra e rededor de la qual sepultura sube tanto como la obra del retablo, asy que bien mirado paresce todo ser engerido en un retablo de bulto. De la otra parte está un bulto de marfil de la reyna su madre, todo el derredor del con letras de oro escolpidas, las quales recuentan su generosidad e nombre e ni más ni menos sube la obra del que acompaña el dicho retablo, asy bien como el sobre dicho del rey don Enrique, en que fazen parescer toda la capilla ser un solo retablo. Yaze por lo alto de cada sepoltura destas dos corredores de clarboya labrado de contillo, pintados a gran maravilla e los cabos de los quales sobre una agilla (águila) de plata toda dorada en que dizen el evangelio e de la otra parte un latril muy alto en que dizen la epístola"2.

Así, por tanto, nos encontramos con un espacio, una capilla dentro de un monasterio que, a la vez que actúa como centro devocional principal de lo que es una de las advocaciones marianas más potentes a fines del medievo, la de la Virgen de Guadalupe, en indisociable conexión, constituye también simultáneamente un ámbito dedicado a la memoria funeraria de un monarca, Enrique IV.

Hay que tener en cuenta que, a pesar de toda la imagen antienriqueña que nos ha legado determinada cronística inmediata a los acontecimientos del reinado de este

1 British Library, Ms. Egerton 620, fols. 55r-57r.

2 Idem., fols. 55rv. 
monarca, su figura, como ocurrió tantas veces en el terreno de la memoria regia, fue objeto de intensa modificación en el transcurso del siglo XVI, gracias al éxito de la crónica que le fue más favorable, la de Diego Enríquez del Castillo. Así, sobre la base de esta crónica y de este proceso de modificación de su recuerdo, encontraremos testimonios en los que podremos leer caracterizaciones de ese monarca en términos rotundamente laudatorios ${ }^{3}$. De hecho, esta reivindicación apelará a la búsqueda en él de manifestaciones destacadas de humanidad, de desprendida generosidad y de una imagen de hombre de paz para un rey que se ofrece como especialmente preocupado por el bienestar de su reino por encima de sus propios intereses personales; afirmándose esta imagen como tópico recurrente en el transcurso de la época de los Austrias ${ }^{4}$. Cabría preguntarse en qué medida el éxito popular de la devoción guadalupana expuesta en la capilla descrita junto al homenaje visual a la memoria enriqueña podría haber influido en esta transformación de su recuerdo.

Del testimonio que acabo de exponer cabe extraer varias valoraciones que interesan especialmente al asunto de las prácticas devocionales de la monarquía con relación a los espacios en que se ejecutaron. Así, destacaría las cinco siguientes:

En primer lugar, formaba parte de la normalidad que espacios típicamente devocionales pudieran ofrecer un mensaje tanto religioso como político.

En segundo lugar, era perfectamente factible el que se produjera una mutua interacción entre lo político y lo religioso en el marco de determinados espacios devocionales, de modo que la presencia de referentes políticos contribuía a dar realce al significado de lo religioso, a la vez que lo religioso podía contribuir a proporcionar un efecto de legitimidad política añadida que tenía una de sus principales manifestaciones en la transformación positiva de la memoria del referente político representado 5 .

En tercer lugar, cuando hablamos de espacios en los que a la vez, por representación o por uso, se constata la presencia de alguna implicación política y religiosa, resulta inevitablemente difícil aplicar al mismo los criterios propios del espacio devocional o del espacio político, en cuanto que incorpora rasgos característicos de uno y de otro.

En cuarto lugar, en cierta medida como consecuencia de lo que acabo de señalar, siendo necesaria la realización de una celebración religiosa relacionada con una conmemoración o con un objetivo de índole política, resultaría especialmente conveniente para la monarquía tomar la opción de elegir para ello una ubicación específicamente religiosa, en tanto que, de este modo, se podría obtener un efecto complementario de legitimación como consecuencia de esa interacción entre lo político y lo religioso, con la que se favorecía un efecto de comunidad de orden religioso superior, de hecho, al meramente resultante de la afinidad política.

Finalmente, en quinto lugar, cabe apuntar que, si la práctica devocional puede ser de índole pública o de índole privada, lo que implica exigencias necesariamente

\footnotetext{
3 British Library, Ms. Additional 15.568., fol. 5r.

4 J. FERNÁNDEZ APARICIO, "Fray Jerónimo de la Cruz y su ‘Crónica de Enrique IV’ (ca. 1650)”, F.J. CAMPOS Y FERNÁNDEZ DE SEVILLA (coord.), La orden de San Jerónimo y sus monasterios: actas del simposium, vol. 2, 1999, pp. 731-749.

5 M. CARRUTHERS, The book of Memory. A Study of Memory in Medieval Culture, Cambridge, 2008.
} 
distintas para lo que se refiere a sus características espaciales y de puesta en escena, dependiendo de esa dimensión pública o privada, la ceremonia política siempre conlleva necesariamente una dimensión pública, lo cual no impide que se pueda hablar de práctica devocional de carácter privado que adquiere alguna forma de valoración política, por cuanto que se desarrolla motivada por la demanda de una instancia política como es el rey o la familia real. Como consecuencia de esto último, un espacio que forma parte de la devoción privada de la familia real, tal como es el caso de las capillas reales, adquiere un significado político, en cuanto que su usuario natural es el rey y la familia real.

Con todo ello, creo que quedan establecidas algunas acotaciones a tener en cuenta cuando se está hablando de prácticas que, protagonizadas por la monarquía, tienen un contenido significativo devocional o religioso y que resultan de interés cuando de lo que se trata, como en este caso, es de hacer valoraciones con respecto al marco espacial en el que tienen lugar 6 .

A partir de aquí, remitiéndome a la experiencia de la Castilla trastámara, de acuerdo con la propuesta de los organizadores, me propongo abordar tres cuestiones relativas, en primer lugar, a los espacios empleados en las ceremonias de dimensión litúrgica de la realeza; en segundo lugar, al uso devocional de las capillas reales y, en tercer lugar, al papel del palacio real con respecto al tipo de ceremonias recién aludidas.

\section{Los espacios de las ceremonias políticas de dimensión litúrgica de la realeza}

Aparte de aquellas ceremonias de la realeza que por su propia naturaleza exigían de algún tipo de formato religioso específico, tales como bautizos, bodas o exequias reales, hubo un variado conjunto de ceremonias que, siendo de índole esencialmente política, también incorporaron alguna forma de expresión litúrgica o religiosa.

Por lo común, las ceremonias de la realeza que acabo de señalar como poseedoras de una naturaleza que por sí misma exigía un formato religioso, tales como bautizos, bodas o exequias reales, se desarrollaron en espacios ajenos al ámbito palaciego, generalmente, en catedrales, salvo rarísima excepción. Así fue expresión de este excepcional uso de espacios no específicamente catedralicios el bautizo de la princesa Juana, la futura Beltraneja, quien fue bautizada en el marco de la capilla real del alcázar de Madrid en $1462^{7}$.

A modo de ejemplo, puede resultar significativo que de las 26 ceremonias de la realeza castellana de esta índole que se reseñan en un trabajo reciente ${ }^{8}$ para el periodo comprendido entre 1383 y 1503, sólo tres se celebran fuera de iglesias, generalmente catedrales, salvo alguna en iglesias monásticas o en iglesias parroquiales, estando

6 Algunas aportaciones de interés relacionadas con las cinco valoraciones que se acaban de enunciar en: P. HENRIET (dir.), A la recherche de legitimités chrétiennes. Représentation de l'espace et du temps dans l'Espagne médiévale (IXe-XIIIe siècle), Lyon, 2003.

7 D. ENRÍQUEZ DEL CASTILLO, Crónica de Enrique IV, A. SÁNCHEZ PARRA (ed.), Valladolid, 1984, cap. XXXVIII, p. 184.

8 D. NOGALES RINCÓN, La representación religiosa de la monarquía castellano-leonesa: la Capilla real, Tesis inédita, Facultad de Geografía e Historia, Universidad Complutense de Madrid, 2009, p. 649. 
referidas, en concreto esas tres al castillo de Burgos y a los alcázares reales específicamente de Madrid y Córdoba.

Sin embargo, si este recurso a espacios específicamente religiosos ajenos al palacio real parece formar parte de lo que sería una pauta normal de actuación, más llamativo puede considerarse que, por lo común, aquellas ceremonias manifiestamente políticas con algún contenido litúrgico, por secundario que éste fuere, también se produjeran en espacios ajenos al palacio real.

Entre las ceremonias políticas de la realeza en las que hubo alguna presencia significativa de práctica litúrgica se pueden sobre todo mencionar los juramentos, los autos, los actos de reverencia simbólica y las misas políticas.

El recurso a los juramentos, en especial durante el siglo $\mathrm{XV}$, se vio rápidamente incrementado como instrumento para la solemnización de pactos políticos en un contexto en el que se hacía especialmente necesario dar seguridades con respecto a su cumplimento ${ }^{9}$. Con su participación en ellos, la monarquía contribuía a asumir un cierto papel de articuladora de alianzas políticas, hasta el extremo de parecer que tal participación suponía una dimensión principal de la propia condición regia durante los reinados de Juan II y Enrique IV ${ }^{10}$.

Dentro de esta práctica del juramento en su creciente relieve político, es indudable que el juramento del rey en el contexto de su ceremonia de proclamación alcanzaba una singularidad excepcional, no sólo por su forma, sino también por sus efectos sobre las relaciones políticas en curso ${ }^{11}$. Aunque esta práctica no contó con tan extensa regulación legal como su importancia política parecía requerir, la Segunda Partida vino a aportar el contenido normativo que seguramente puede considerarse como más relevante y duradero ${ }^{12}$. Elemento esencial en su desarrollo ceremonial para producir sus objetivos de solemnidad legitimadora era hacer bien palpable la simultaneidad de una dimensión humana y divina del acto ${ }^{13}$. Por todo ello, la presencia de un marco religioso susceptible de utilización política y la intervención relevante de un mediador clerical parecían venir recomendados por las exigencias que se acaban de enumerar.

Con relación a sus contenidos rituales concretos, puede afirmarse que hubo bastante estabilidad en cuando a las formas concretas de ejecución como efecto directo de los requisitos que se acaban de enumerar. En consecuencia, lo habitual fue realizarlo ante los Evangelios, la cruz y la presencia de un prelado y, generalmente, dentro o en el entorno de un templo, iglesia, catedral o monasterio, tratándose de un juramento que se planteaba como compromiso con el reino, cuya representación de grandes y nobles, prelados y procuradores de las ciudades habría acudido al acto, por lo común,

\footnotetext{
9 Estas mismas consideraciones pueden verse más por extenso en J.M. NIETO SORIA, "El juramento real de entronización en la Castilla Trastámara (1367-1474)", Europa e Italia. Studi in onore di Giorgio Chittolini, Florencia, 2011, pp. 371-384.

10 Sobre la práctica ceremonial de los distintos tipos de juramento político en J.M. NIETO SORIA, Ceremonias de la realeza. Propaganda y legitimación en la Castilla Trastámara, Madrid, 1993, pp. 59-69.

11 A.I. CARRASCO MANCHADO, "Palabras y gestos de compromiso: los reyes castellano y sus juramentos (siglo XV)", e-Spania, 4 (2007), p. 3.

12 Siete Partidas, Partida II, título XV, leyes 4 y 5.

13 J.M. NIETO SORIA, op.cit., 1993, pp. 67-68.
} 
como respuesta a una convocatoria de Cortes, en cuyo seno se llevaba a cabo esta ceremonia.

En consecuencia, a pesar del perfil político, la presencia de una cierta e insoslayable dimensión litúrgico-religiosa determinó que esta ceremonia, de tan relevante importancia constitucional, se ejecutase fuera del marco palacial, priorizando la opción de un edificio de carácter marcadamente religioso.

El auto político ${ }^{14}$ supone el desarrollo de una ceremonia que se rodea de una solemnidad particular, a fin de dotarse de referentes representativos mediante los cuales se pretende obtener un efecto legitimador añadido. Es por ello que no fue extraño que para tales actos ceremoniales convocados al efecto de reconducir una determinada situación política se acudiera a dotar de alguna forma de contenido religioso estos autos, por cuanto que de ese modo se podía obtener ese efecto legitimador añadido. En este sentido, también conviene tener presente la creciente presencia de las prácticas teatrales en el medio cortesano en forma de momos y de otras representaciones lúdicas, con protagonismo de los principales personajes del entorno regio, e incluso del propio monarca, en especial durante la época de Juan $\mathrm{II}^{15}$, no faltando aquéllas que tenían una temática específicamente religiosa, con lo que se favorecía un ambiente más propicio al consenso ${ }^{16}$.

Una expresión especialmente adecuada como manifestación de lo que se acaba de señalar fue el auto de Ávila celebrado en su catedral. Tal como señaló Julio Valdeón ${ }^{17}$, el infante don Enrique, al promover la convocatoria de unas Cortes celebradas a comienzos de agosto de 1420, buscaba sancionar el denominado golpe de Tordesillas de la madrugada del 14 de julio. En consecuencia, se recurrió a una puesta en escena propia de unas Cortes, pero con insólitos rasgos ceremoniales convenientes a los objetivos de una convocatoria que buscaba legitimar el procedimiento por la vía del recurso a la fuerza, por el que el rey quedaba, de hecho, bajo el control del infante don Enrique y sus aliados ${ }^{18}$.

Celebrado este acontecimiento en alguna fecha comprendida entre el 4 y el 11 de agosto de 1420, bajo una apariencia de convocatoria de Cortes, se constata la presencia de esta búsqueda de extraordinaria solemnidad mediante el despliegue de diversos instrumentos celebratorios. Así, sabemos que "fízose trono é asentamiento alto de madera en la iglesia catedral de la cibdad de Avila, donde el Rey se asentó en su silla real", lo que nos sitúa ante la celebración de unas Cortes en el marco de una catedral, en el contexto de una voluntad, sin duda, nada casual, de dar una dimensión eclesiástica y religiosa al acontecimiento político.

14 Véase desde el punto de vista definitorio de este término sus diversas acepciones en: M. ALONSO, Diccionario Medieval Español. Desde las Glosas Emilianenses y Silenses (s. X) hasta el siglo XV, Salamanca, 1986, I, p. 450.

15 A. GÓMEZ MORENO, El teatro medieval románico en su contexto castellano, Madrid, 1991.

16 Algunos ejemplos en: T.F. RUIZ, A King travels: festive traditions in late medieval and early modern Spain, Princeton, 2012.

17 J. VALDEÓN BARUQUE, "Las cortes de Castilla y las luchas políticas del siglo XV (1419-1430)", Anuario de Estudios Medievales, 3 (1966), pp. 304-305.

18 J.M. NIETO SORIA, "El auto de Avila de 1420”, M.I. DEL VAL VALDIVIESO y P. MARTÍNEZ SOPENA (dirs.), Castilla y el mundo feudal. Homenaje al Prof. Julio Valdeón, Valladolid, 2009, vol. II, pp. 679-690. 
Tras una brevísima intervención del propio monarca ${ }^{19}$, limitada a dar la palabra, todo el peso del acto se confía a la alocución pronunciada por el arcediano de Guadalajara, don Gutierre Álvarez de Toledo ${ }^{20}$, destacado miembro de un linaje que va adquiriendo por aquellos años pujanza creciente, como es el de los Álvarez de Tole$\mathrm{do}^{21}$. La intervención del mencionado don Gutierre Álvarez de Toledo, tal como se describe en los textos cronísticos que dan noticia de ello, tiene un formato enteramente eclesiástico, teológico y litúrgico. Habla desde el púlpito, su alocución se hace $a$ manera de sermón, siendo, además, pronunciado en latín, lo que no era común en los discursos de apertura de Cortes en la Castilla de la época, aportando abundantes referencias de la Sagrada Escritura, de obras de los Doctores de la Iglesia, así como del Derecho Canónico. Todo ello, por tanto, nos sitúa ante la instrumentalización política de una representación litúrgica.

Es para el final de su sermón para cuando don Gutierre deja la consideración de lo que han sido las circunstancias políticas recientes que habrían motivado el golpe de Tordesillas que ahora se justificaba. Algunas iniciativas que siguieron al auto de Ávila permiten comprobar su importante significación en el contexto de los proyectos políticos inmediatos del partido del infante don Enrique. Así se pone de relieve en las dos iniciativas políticas más relevantes que tienen lugar en los días siguientes, como fueron la de abrir negociaciones con el partido de los otros infantes de Aragón, don Juan y don Pedro ${ }^{22}$, por un lado, y el envío de una embajada a la curia pontificia ${ }^{23}$. Con todo ello se completaba el proceso de legitimación del cambio de fuerzas y de protagonismos que se había producido en la corte castellana tras el Golpe de Tordesillas.

En definitiva, tal como se ha podido comprobar a partir del ejemplo considerado, en el caso de la celebración de un auto de elevado perfil político, en el que realmente se está justificando un cambio político sustancial, se lleva a cabo un acto ceremonial en el que se manejan elementos de legitimidad religiosa, desplegándose toda la solemnidad necesaria en el marco, no del palacio real, sino de una catedral, lo que seguramente se valoró como la opción más adecuada para aportar legitimación espacial a

\footnotetext{
19 "Perlados, Caballeros é Procuradores que aquí estáis, yo vos mandé aquí llamar por las razones que largamente vos dirá de mi parte el Arcediano de Guadalajara, al qual yo mandé que vos dixese en mi presencia lo que agora vos dirá". F. PÉREZ DE GUZMÁN, Crónica de Juan II, Biblioteca de Autores Españoles, LXVIII, Madrid, 1953, p. 387. Ligeras variantes con la alocución regia, según García de Santa María: "Yo vos mandé ayuntar aquí por las razones que largamente vos dirá el Arcediano de Guadalajara, al cual yo mandé que vos las dixese aquí delante de mí en este ayuntamiento". A. GARCÍA DE SANTA MARÍA, Crónica de Juan II de Castilla, Colección de Documentos Inéditos para la Historia de España, XCIX, Madrid, 1891, I, pp. 130.

20 Será este personaje quien inaugurara el título de Alba por concesión regia: J.M. NIETO SORIA, Un crimen en la corte. Caída y ascenso de Gutierre Álvarez de Toledo, Señor de Alba (1376-1446), Madrid, 2006.

21 Archivo Ducal de la Casa de Alba, leg. 222, doc.5.

22 A. GARCÍA DE SANTA MARÍA, op. cit. 1891, I, pp. 132-134; y F. PÉREZ DE GUZMÁN, op. cit., 1953 , p. 387.

23 A. GARCÍA DE SANTA MARÍA, op. cit., 1891, I, pp. 134-135; y J.M. NIETO SORIA, op. cit., 2006, pp. 184-187.
} 
los objetivos políticos pretendidos en un contexto no exento de resistencias y sometido a evidente tensión de fuerzas ${ }^{24}$.

Es verdad, tal como se ha visto, que estamos en este caso ante un cierto contexto político de excepcionalidad, en cuanto que se trataba de dar cobertura institucional mediante una apariencia de Cortes que se pretendía respondieran a una imagen de normalidad política, por lo que la puesta en escena de especial dimensión litúrgica parecía especialmente conveniente, por lo que la elección de un marco eclesiástico para la propia celebración de las Cortes, conectado, además, con un relevante envoltorio litúrgico podía considerarse más que justificado. Sin embargo, la elección de esa espacialidad celebratoria no tenía mucho de excepcional o de anómalo, en cuanto que la celebración de Cortes en marcos eclesiales, bien fueran catedrales o iglesias de diversa índole, formó parte de una práctica bastante extendida en toda la época.

Por otra parte, es difícil no encontrar evidentes paralelismos entre este auto de Ávila de 1420 y las Cortes de Burgos de 1367, convocadas por Enrique de Trastámara para refrendar sus derechos al trono, tras el comienzo de la guerra civil contra Pedro I. De nuevo se buscó un espacio de solemnidad inatacable y que procuraba un evidente refrendo sagrado, extrapolítico, recurriendo, en este caso, a su celebración en el claustro de la catedral de Burgos ${ }^{25}$.

Las ceremonias litúrgicas de reverencia simbólica son las que suponen la celebración de actos de contenido litúrgico relevante, en los que se expresa una actitud devocional por parte del monarca hacia algún símbolo político al que se dota de significación religiosa o hacia algún símbolo religioso en el que se advierte alguna significación política.

Ya en las Cortes de Briviesca de 1387 quedaron establecidas algunas pautas de comportamiento ceremonial con respecto a diversas casuísticas. Así, por ejemplo, las referentes a cómo debería actuar el rey ante la presencia de la sagrada forma en un espacio público ${ }^{26}$ o qué contenidos litúrgicos deberían ser tenidos en cuenta para la recepción del rey en su llegada a una ciudad, describiéndose las pautas rituales que debería seguir el clero de esa ciudad al respecto ${ }^{27}$.

La espada del rey don Fernando III conservada en la catedral de Sevilla fue objeto de distintos actos de reverencia simbólica con motivo del inicio de algunas campañas en la frontera, así, por ejemplo, la protagonizada por el infante don Fernando como tutor real, en $1407^{28}$. Custodiada esta espada por el cabildo catedralicio sevillano, para su recepción por el infante se llevó a cabo una solemne procesión desde el coro hasta el altar mayor, donde se había ubicado un estrado cubierto con paños de oro, sucediéndose varias solemnidades dentro de la catedral sevillana con presencia de todo el cabildo catedralicio, miembros de la corte y autoridades locales, produciéndose, además, la

24 Véase al respecto con extenso desarrollo fáctico de estos acontecimientos: S. GONZÁLEZ SÁNCHEZ, La Corona de Castilla: vida politica (1406-1420). Acontecimientos, tendencias y estructuras, Tesis Doctoral, Universidad Complutense de Madrid, 2010, consultable en http://eprints.ucm.es.

25 "Estando todos ayuntados connusco en las dichas Cortes en la claostra dela iglesia de Santa María la catedral dela dicha çibdat de Burgos". Cortes de los antiguos reinos de León y Castilla, Madrid, 1863, II, p. 145 .

26 Ibid., p. 363, ley 2.

27 Ibid., II, p. 363, ley 1.

28 A. GARCÍA DE SANTA MARÍA, op. cit., 1891,cap. 48, p. 131. 
jura del infante en la que manifestó su compromiso de devolverla acabada la campaña. Finalmente, se daría proyección popular al acontecimiento con la salida al exterior del tutor portando la espada para mostrarla a la multitud allí congregada.

En términos similares a lo que se acaba de señalar para la espada de un monarca con recuerdo particularmente prestigioso, tampoco faltan las alusiones a los pendones como sujeto de reverencia simbólica que motiva el desarrollo de ceremonias litúrgicas con presencia regia. Así se desarrollarán ceremonias específicas para la bendición de pendones reales, muchas veces guardados dentro de templos y exhibidos en el marco de procesiones solemnes. Así, por ejemplo, se nos narra el caso de los días anteriores al comienzo de la campaña que llevaría a la victoria de la Higueruela en 1431, antes y después de la cual se sucederían diversas ceremonias públicas protagonizadas tanto por Juan II como por Álvaro de Luna ${ }^{29}$.

Del mismo modo, tras haber hecho entrada Juan II y don Álvaro de Luna en Toledo el 15 de abril ${ }^{30}$, transcurrida una semana, el rey hizo la vela de sus armas y sus pendones en la catedral, ante el altar de Santa María del Pilar. Al día siguiente oyó misa rezada y, además de realizarse la bendición de la espada y de la cota de armas del condestable, se pusieron sobre el altar el pendón real, el de Santiago, el de la Banda y uno que respondía a una invención del monarca, el pendón del ristre, seguramente alusivo a este elemento de fijación de las armaduras caballerescas, elevado ahora a símbolo de una enseña regia. Tras la misa oficiada por el obispo de Ávila Diego de Fuensalida, se procedió a bendecir las armas y la cota del rey, así como los pendones, haciéndose una predicación por el arcediano de Toledo Vasco Ramírez de Guzmán.

De manera similar, también fueron objeto de atención ceremonial mediante la que se expresaba esa reverencia simbólica, pendones de santos, en el caso de Castilla, principalmente los de Santiago y san Isidoro, bien en el marco de actos litúrgicos celebrados dentro de distintas catedrales o en el desarrollo de procesiones por determinadas ciudades $^{31}$.

Ceremonias igualmente expresivas de reverencia simbólica se produjeron asociadas a las peregrinaciones regias a determinados lugares de culto, adquiriendo un relieve creciente durante la época trastámara las destinadas precisamente al ya aludido monasterio de Guadalupe. En tal sentido, se cuenta con dos descripciones que narran con algún detalle el desarrollo de la peregrinación allí realizada por Juan II en febrero de 1435, teniendo lugar una ceremonia de recepción mediante una procesión en la que participaron ciento veinte frailes, antes de que el monarca penetrase en el templo ${ }^{32}$.

Por último, dentro de las ceremonias políticas de contenido litúrgico, cabe destacar la presencia de misas políticas, de forma que el centro principal de la ceremonia vino precisamente definido por la celebración de una misa especialmente solemne durante la

29 J.M. NIETO SORIA, "El ciclo ceremonial de la batalla de la Higueruela (1431)", Estudios de Historia de España, 12 (2010), pp. 389-404.

30 La descripción de los acontecimientos desarrollados en Toledo en P. CARRILLO DE HUETE, Crónica del Halconero Juan II, J. DE MATA CARRIAZO (ed.), Madrid, 1946, pp. 90-91.

31 F. PÉREZ DE GUZMÁN, op. cit., 1953, año IV, cap. XXX, p. 328; y F. GÓMEZ DE CIBDARREAL, “Centón epistolario", Epistolario Español, B.A.E., vol. XIII, Madrid, 1945, epístola LI (año 1431).

32 F. PÉREZ DE GUZMÁN, op. cit., 1953, año XXVIII, cap. X, p. 519; y P. CARRILLO DE HUETE, op. cit., 1946, cap. CLXXIX, p. 195. 
cual se daba lugar a alguna expresión política que constituía la justificación misma de la ceremonia, generalmente con presencia de buena parte de los miembros de la corte, junto con los miembros de la familia real y con una extensa asistencia del clero y autoridades locales. De este modo, llegado a un determinado momento en el desarrollo de la misa, se daba lugar a la celebración de un juramento, al otorgamiento de determinado cargo mediante alguna expresión simbólica, a la bendición de objetos simbólicos, en especial pendones, a la predicación de alguna homilía de sentido político preciso, a la concesión de algún perdón de significación política, o a la predicación de una bula de cruzada, entre otras posibles manifestaciones políticas ${ }^{33}$.

En definitiva, tal como se ha podido ver a partir de distintas manifestaciones de ceremonias políticas de contenido litúrgico o ceremonial, su marco típico de plasmación se sitúa sobre todo en la catedral, pudiéndose considerar como el espacio natural destinado a su celebración. Son, con mayor frecuencia, catedrales especialmente relevantes del reino, como Toledo, Burgos o Sevilla, las que destacan como ubicaciones recurrentes para llevar a cabo estas solemnidades, sin que falten otras utilizadas por razón de urgencia u oportunidad como Ávila, León o Santiago. Más raramente, encontramos también algún centro monástico con especial relieve devocional en las prácticas ceremoniales de la realeza, tal como, por ejemplo, sucede con Guadalupe, las Huelgas de Burgos o San Pablo de Valladolid, que serán ocasionalmente utilizados como espacios también afines a este tipo de usos. Bien al contrario, el palacio real, salvo de una manera muy excepcional y poco significativa, no parece ser el destino natural de este tipo de actos representativos de la realeza.

\section{Las capillas reales palaciales en la práctica devocional de la realeza}

Durante la época trastámara la presencia de una capilla en cada palacio real se convirtió en la práctica habitual. De este modo, se fue asegurando y multiplicando la presencia de un considerable número de capillas reales que se extendían por el conjunto del reino, tanto en los edificios remozados como en aquellos otros construidos expresamente para actuar como residencias regias ${ }^{34}$. Tal como se observa en el caso del alcázar de Madrid, la construcción de un espacio particular destinado a capilla real está perfectamente previsto en el proyecto constructivo inicial, en la medida en que algo podemos saber de él durante el reinado de Enrique III, a través de alguna carta en la que se recoge alguna telegráfica referencia al retraso para la terminación de la construcción de la capilla del alcázar de acuerdo con los deseos del monarca: "Et señor, la obra de la capilla non se podrá acabar en este dicho tiempo, mas, señor, dar se ha en ello grande acuçia por que se acabe lo más çedo que ser se pueda" 35 .

Gracias a la Tesis Doctoral de David Nogales Rincón, disponemos de una evaluación bastante precisa sobre el uso ceremonial de las capillas reales palatinas en el caso del

\footnotetext{
33 Sobre esta actividad ceremonial más por extenso: J.M. NIETO SORIA, op. cit., 1993, pp. 88-93.

34 Puede verse una relación completa de las capillas reales documentadas para la monarquía castellanoleonesa en D. NOGALES RINCÓN, op. cit. 2009, pp. 337-360.

35 ARCHIVO GENERAL DE SIMANCAS (AGS), Estado-Castilla, leg. I- ${ }^{\circ}$, fols. 8 y 10.
} 
reino castellano-leonés ${ }^{36}$. De acuerdo con el mencionado autor, las referencias a la celebración de ceremonias religiosas de relieve político en el marco de las capillas reales palatinas, tanto para la época trastámara como, en general, para todo el conjunto de la época medieval, resultan extraordinariamente escasas, ratificándose así la impresión que ya se adelantaba antes, al estudiar las ceremonias litúrgicas de la monarquía trastámara en el sentido de que éstas, por lo común, no se realizaban en espacios palaciales, a pesar de la disponibilidad en ellos de lugares específicamente religiosos como eran las capillas reales. Bien por el contrario, fueron, por lo común, sobre todo catedrales y, en menor medida, templos parroquiales o monásticos los destinados a tal función. A ellos, en ocasiones, se sumarían altares improvisados cuando por razones de desplazamiento, no cabía disponer de alguno de estos edificios.

De este modo, el uso religioso de las capillas palatinas por parte de la monarquía quedaría reducido a celebraciones de carácter ordinario, ajenas a lo que eran grandes solemnidades de relieve político. Se trataría, por tanto, de las celebraciones propias de las misas ordinarias, así como otras de mayor solemnidad que venían exigidas por el calendario litúrgico que, en definitiva, responderían a lo que cabría entender como las festa ferienda $a^{37}$. De hecho, consideraciones similares ha planteado desde una perspectiva peninsular Rita Costa-Gomes, teniendo especialmente presente la experiencia portuguesa ${ }^{38}$.

La revisión de las distintas ordenanzas y constituciones que se pueden manejar permiten pensar igualmente en este tipo de funcionalidad, al dedicarse capítulos específicos a la celebración de las misas ante los monarcas o cómo debían efectuarse los servicios cuaresmales o de semana santa, entre otros ${ }^{39}$.

A pesar de esta, si se quiere decir así, falta de solemnidad política de esta actividad cotidiana de las capillas palatinas, esto no era impedimento para que las previsiones en cuanto a la forma de realizarse los distintos actos litúrgicos comportasen una estricta planificación, atendiendo a la especial dignificación del acto que venía exigida por la mera presencia regia. Además de la concurrencia de un número adecuado de capellanes, así como de músicos y cantores, resulta, por ejemplo, relevante la constatación de testimonios que aluden a la estricta jerarquización de los asistentes dentro del espacio de la capilla ${ }^{40}$.

La voluntad de solemnización de los actos litúrgicos realizados en la capilla real y de demarcación espacial de la jerarquía dentro de ella estuvo presente en los distintos reinos hispánicos, y no sólo en éstos. Así, se utilizarían elementos destinados a marcar y resaltar la ubicación del rey dentro de la capilla, bien de una manera fugaz, con la dis-

36 D. NOGALES RINCÓN, op. cit., 2009, pp. 640-715.

37 D. NOGALES RINCÓN, op. cit., 2009, p. 655.

38 R. COSTA GOMES, "The Royal Chapel in Iberia: Models, Contacs and Influences", The Medieval History Journal, 12 (2009), 77-111.

39 Ejemplo de ello en las constituciones de 1436 en J.M. NIETO SORIA, "La capilla real castellanoleonesa en el siglo XV: constituciones, nombramiento y quitaciones", Archivos Leoneses, 85-86 (1989), pp. 19-20.

40 Ejemplo de ello con relación a la capilla real de Isabel la Católica en: L. MARINEO SÍCULO, De las cosas ilustres y excelentes de España, Lib. XXI, fol. 183r. Cit, en D. NOGALES RINCÓN, op. cit., 2009 , p. 668. 
posición de unas cortinas tras las cuales quedaba aislada dentro del espacio de la capilla la persona de los monarcas, o bien, en otras ocasiones, ya de una forma permanente, esta función quedará asegurada mediante un balcón donde se ubicaba el rey de manera separada y en una altura por encima del resto de los participantes en el acto litúrgico ${ }^{41}$.

\section{El palacio real en la práctica devocional de la realeza}

Pocas definiciones más precisas por su objeto, a la par que ambiguas por su contenido concreto, cabe encontrar para cómo se entendía desde una perspectiva institucional lo que era el palacio real que la que ofrece la Segunda Partida ${ }^{42}$. Considerando tal definición, estaríamos en presencia de una cierta forma de personalización del palacio del rey en función de la propia persona del monarca, resultando, por tanto, inadecuado limitar tal concepto a una identificación exclusiva de éste con lo que serían espacios físicos permanentes utilizados como sedes regias habituales.

Esta acotación resulta relevante al objeto de no perder de vista que, en el contexto bajomedieval, el concepto de palacio real, tal como hoy lo pudiéramos entender, es decir, como espacio arquitectónicamente singular, especialmente concebido para una puesta en escena solemne del rey, podría considerarse como una cierta forma de anacronismo con respecto a lo que era el universo conceptual de la época si se considerase bajo términos de exclusividad para el palacio real tal función. Por el contrario, se entendía que la presencia del rey siempre debía conllevar una dimensión solemne, la cual, en ocasiones, exigía de determinados marcos espaciales, no siendo siempre necesariamente el palacio real el más adecuado, dependiendo de las circunstancias y de los objetivos que se pretendiesen.

A partir de las consideraciones que se acaban de apuntar se podrá comprender algo enormemente importante desde la perspectiva de los usos ceremoniales de la monarquía. Esto es, que desde la perspectiva regia el palacio real como edificio concreto podía identificarse con cualquier espacio permanente u ocasional, de titularidad real o no, en el que en un momento dado se realizaba alguna de las funciones señaladas en la Segunda Partida, o que, de manera más amplia, era utilizado para llevar a cabo alguna forma de puesta en escena de la monarquía en un contexto de proyección pública de mayor o menor dimensión. De este modo, la monarquía podía considerarse como dentro de tal palacio real cuando se hallaba en lugares tales como podía ser un monasterio o una catedral, los cuales, en el marco de todo un desarrollo ceremonial con la presencia del rey y de la corte, se convertían en una expresión genuina del palacio real. En consecuencia, con ello nos encontraríamos ante el hecho de que la presencia del rey y el carácter solemne del acto realizado imponían la condición palacial.

Por otra parte, el deseo de la monarquía de convertir el entorno regio en una realidad cada vez más definida y regulada, llevó a Juan II a establecer una delimitación precisa del número de individuos que podían estar presentes en la corte, resultando, en cualquier caso, una cifra elevada que exigía de una espacialidad adecuada a su acogi-

41 R. COSTA GOMES, op. cit., 2009, pp. 97-102.

42 Siete Partidas, part. II, tít. IX, ley XXIX. 
miento ${ }^{43}$. Con ello, de nuevo, se volvía a dar un indicio de lo determinante del factor personal en la categorización del hecho espacial. Precisamente este tipo de regulaciones en las que se establece lo que debe ser el entorno personal del rey nos remite, de nuevo, a lo que era un planteamiento que se abstraía del hecho espacial, para concentrarlo en esa idea central de la Segunda Partida que remitía la idea de palacio real no a un lugar concreto, sino a un entorno personal regulado por unos comportamientos, unas pautas y unos objetivos de actuación.

Desde otra perspectiva, como era la relacionada con las necesidades impuestas por la itinerancia regia, unidas a la exigencia de disponibilidad por el rey de espacios adecuados, no sólo para garantizar una cierta comodidad y solemnidad para el cortejo real, sino también para obtener la conveniente seguridad en contextos frecuentes de alteración política, se propició que, en el transcurso de la baja Edad Media, el modelo de alcázar real, bien resultado del remozamiento de construcciones ya antiguas de origen sobre todo musulmán, o bien como efecto de nuevas iniciativas constructivas, se convirtiera en la manifestación más característica de lo que se podría considerar como típica expresión de una sede regia ${ }^{44}$. Aunque dotados estos edificios habitualmente de capilla real, en escasa medida ésta podía ofrecer el escenario adecuado a lo que eran solemnidades devocionales y religiosas de la monarquía en las que ésta se situaba en el centro de toda una puesta en escena en la que religión y política, como ya he señalado, interactuaban de una manera relevante en un marco de considerable dimensión pública.

\section{Conclusiones}

Terminemos, antes de plantear algunas conclusiones finales de conjunto, haciendo referencia a un acontecimiento político situado al final del marco cronológico aquí considerado que, tanto por sus contenidos, como por su significado en el contexto de la evolución de la génesis del Estad Moderno, puede considerarse como relevante dentro de las cuestiones aquí abordadas.

En 1480 tiene lugar un conjunto que actos ceremoniales de decisivo valor político en el proceso de legitimación de la sucesión de Isabel y Fernando tras la guerra con Portugal, no exenta de rasgos propios de guerra civil, desarrollada a poco de la muerte de Enrique IV. Me refiero a las Cortes de Toledo de 1480, en torno a cuya celebración se llevaron a acabo otros muchos actos de interés tanto político-administrativo como de puesta en escena de la monarquía. En este caso, la ciudad elegida ofrecía extensas $\mathrm{y}$ variadas posibilidades en cuanto a la disponibilidad de edificios palaciegos ${ }^{45}$. Varios de estos palacios serían objeto de utilización para atender a las necesidades políticas de los monarcas. Habiéndose alojado los reyes en las casas de López de Ayala. A pesar

43 J.M. NIETO SORIA (dir.), Orígenes de la Monarquía Hispánica: propaganda y legitimación (ca. 14001520), Madrid, 1999, doc. 40.

44 M.A. LADERO QUESADA, Los alcázares reales en las ciudades de Castilla (siglos XII a XV), Segovia, 2002.

45 Puede encontrarse detallada enumeración de esos espacios palaciegos toledanos en: J. PASSINI, "Los palacios urbanos medievales en Toledo", J. PASSINI y R. IZQUIERDO BENITO (coords.), La ciudad medieval de la casa principal al palacio urbano, Toledo, 2011, pp. 219-240. 
de los testimonios, no siempre coincidentes que atienden a estos acontecimientos, este alojamiento real debió de ser el epicentro de la actividad personal de los monarcas, así como de muchos de sus consejeros, dando cabida a numerosas reuniones. Sin embargo, a pesar de esa extensa disponibilidad palaciega y de esa función central del mencionado palacio ahora habilitado como residencia regia y como centro de negociación de los importantes asuntos políticos que habían de ventilarse, cuando de lo que se trata es de llevar a cabo ceremonias solemnes en donde pueda estar presente algún contenido litúrgico, habrá de buscarse el espacio sagrado. Sabemos que las reuniones generales de Cortes tuvieron lugar en la iglesia de San Pedro Mártir, que ya tenía cierta tradición en tal función. Pero, probablemente, el acto político más solemne, con presencia significativa de dimensión litúrgica, fue el de la jura del príncipe Juan. Ésta tendría lugar en la catedral toledana el 6 de febrero. A lo largo de lo que debió de ser una larga ceremonia se sucedieron misa solemne y sermón, juramento de obediencia y fidelidad de los procuradores, besamanos al príncipe, juramento de cumplir el testamento de la reina y distintos pleito-homenajes en manos del duque de Villahermosa. Seguidamente, ya delante de la puerta del perdón de la catedral, se efectuaría un acto exclusivo para los procuradores toledanos con su juramento y su pleito-homenaje en manos del condestable de Castilla.

Sólo los juramentos de personajes ausentes se realizarían ya más tarde, el 26 de abril, sin duda, en términos mucho menos solemnes, teniendo acogida en "las casas donde posan los reyes" ${ }^{46}$.

Así, en este tardío momento, y en un contexto tan significativo en la evolución de la génesis del Estado Moderno en Castilla se comprobaría de nuevo cómo las exigencias rituales y el particular significado político de las ceremonias de la realeza que tenían una inevitable dimensión litúrgica y pública, seguían encontrando su marco idóneo y preferente en un espacio eclesial ajeno al palacio y residencia regia.

Tras esta última comprobación, convendrá precisar algunas consideraciones conclusivas con las que cerrar nuestro somero análisis.

Desde el punto de vista de las necesidades de las prácticas devocionales de la monarquía, estaba prevista la existencia de una institución específicamente dedicada a atender las necesidades espirituales de la familia real y de los miembros de la corte, tal como se ha dicho: la capilla real.

Tal vez no sea casualidad que la regulación sobre quiénes deban estar presentes en la corte y la emisión de unas primeras ordenanzas regulando el funcionamiento de la capilla real ${ }^{47}$ se produzcan en fecha bien próximas. Las primeras, las referidas a la calidad y número de personas con derecho a permanecer en la corte, en 1440, y las segundas, las referidas a la regulación de las capillas y los capellanes reales, en 1436, y en un contexto general de reorganización de todo lo que era el conjunto de la administración

46 Todos estos acontecimientos han sido objeto de especial desarrollo desde el punto de vista de sus contenidos rituales en: J.M. CARRETERO ZAMORA, Cortes, monarquía, ciudades. Las Cortes de Castilla a comienzos de la época moderna (1476-1515), Madrid, 1988, pp. 142-189; y A.I. CARRASCO MANCHADO, Isabel I de Castilla y la sombra de la ilegitimidad. Propaganda y representación en el conflicto sucesorio (1474-1482), Madrid, 2006, pp. 437-445.

47 J.M. NIETO SORIA, op. cit., 1989, pp. 7-54. 
regia, tal como sucedió en las Cortes de Guadalajara de $1436^{48}$, lo que denota, una vez más, la preocupación de la monarquía por un marco regulado en lo que era el entorno inmediato de las actividades cotidianas del monarca.

Sin embargo, tal como se ha podido comprobar, esa función parecía estar más concebida desde el punto de vista de las necesidades específicas de la familia real y del personal cortesano, que desde lo que podían ser las exigencias institucionales de una monarquía que cada vez precisaba de mayor dimensión pública, en definitiva, de mayor ostentación de la capacidad de generar una representación, no sólo de su poder efectivo, sino también del poder pretendido.

La devoción religiosa, cuando es ejercida por la monarquía en un contexto de propiciar una devoción política y de ofrecer una forma de representación sublimada del poder monárquico precisa de unos espacios mucho más amplios, abiertos y accesibles que lo que eran las características de los palacios reales de la época trastámara. De esta manera, esa expresión de devoción religiosa monárquica podía alcanzar unos marcos sociales de difusión muchos más amplios y, por ello, mucho más útiles desde el punto de vista de las necesidades de representación de la propia monarquía. Con ello, además, se conseguía un efecto social y políticamente inclusivo, al tratarse de espacios poseedores de una solemnidad colectivamente asumida que procuraban un efecto añadido de legitimación.

De este modo, tal como se ha podido comprobar, la grandes ceremonias de contenido litúrgico y religioso de la realeza se produjeron al margen de los límites impuestos por el espacio palacial, favoreciendo con ello unas posibilidades de integración política para esas prácticas ceremoniales que con frecuencia buscaban exceder el ámbito exclusivo de los miembros de la corte, y que no habrían sido posibles en la reclusión del palacio regio.

En consecuencia, tal como se ha visto, la construcción de las capillas reales palatinas no estaría planteada en función de lo que era la representación ceremonial de la monarquía, sino en función de unas necesidades espirituales privadas cotidianas, que aseguraban la inmediatez de una asistencia espiritual y de una práctica religiosa más o menos asidua, para las que el palacio contaba con este marco específico y adecuado. A la vez, también responderían a la necesidad de dar expresión simbólica a lo que el referente religioso suponía en la legitimación misma de la monarquía, lo que hacía que el palacio real, en tanto que símbolo de la monarquía, integrase como un elemento característico una capilla real.

La necesidad de una proyección pública de la monarquía era difícilmente enmarcable en el contexto de la época en los límites del espacio palacial, lo que era consecuencia directa de la propia evolución del modelo monárquico. En efecto, en el marco histórico de la evolución política de la época trastámara resultaban evidentes las nuevas necesidades de consenso en un contexto de diversidad de modelos políticos ${ }^{49}$ y de nuevos retos de transformación que obligaba a la monarquía a que, cualquiera que fuera su opción, más o menos populista, más o menos aristocratizante, más o menos absolutista, precisara de

48 F. PÉREZ DE GUZMÁN, op. cit., 1953, pp. 529-532.

49 J.M. NIETO SORIA, "Three models of Monarchy in fifteenth-century Castile", P.C.M. HOPPENBROUWERS (ed.), Essays in Honnour Prof. Wim Blockmans, Turnhout, 2010, pp. 85-102. 
la escenificación de unos consensos, ciertos o aparentes, que exigían de una puesta en escena de amplia proyección pública.

Desde esta perspectiva, si el uso del palacio real podía hacerse comprensible en el marco de lo que eran ceremonias específicamente políticas que precisaban de una solemnización política proyectada sobre un círculo inmediato a la persona regia que podía verse luego compensada por el desarrollo de actividades festivas con posibilidades más extensivas e integradoras, tales como entradas reales, juegos de cañas, ocupación festiva de espacios públicos...; el palacio real, aplicado a una ceremonia religiosa de la monarquía, podía percibirse como un instrumento de exclusión y de difícil compatibilidad con la escenificación del consenso, mientras que el edificio religioso, aunque fuera usado en la práctica ceremonial con la sola presencia del entorno cortesano, si bien casi siempre daba entrada a la participación de las autoridades locales, no dejaba de ser un espacio reconocible como propio de todos los integrantes de la societas christiana, sin exclusiones, en el que se representaba un universo religioso compartido y reconocible, bien distinto de lo que era la exclusividad palaciega.

Por ello, en nuestra opinión, la catedral, y no el palacio real, se convirtió en el espacio más recurrentemente utilizado para llevar a cabo las principales ceremonias litúrgicas y devocionales de la monarquía con los Trastámara cuando éstas pretendían proyectar un marcado mensaje político y producir una cierta suerte de devoción religiosa en torno al poder real. En cualquier caso, tal vez no resulte demasiado conveniente establecer contraposiciones entre catedral y palacio real cuando lo que se está valorando es la puesta en escena de la monarquía bajo referentes religiosos. En efecto, las catedrales más importantes del reino contaban con capillas reales que daban una cierta connotación palaciega al propio espacio catedralicio. Del mismo modo, la catedral no dejaba de convertirse, de hecho, en una forma de palacio real cuando lo que se llevaba a cabo en ella era una celebración religiosa protagonizada por la monarquía. Si se consideraba que el palacio del rey estaba allí donde el monarca se manifestaba bajo formas de solemnidad regulada, la catedral se convertía en esas ocasiones en un palacio real en toda su plenitud en el que, además, se podía producir un efecto extraordinario de integración socio-política especialmente conveniente a los intereses representativos de una monarquía que se ofrecía como centro de conciliación y consenso en un contexto cotidiano de confrontación y de diferencia.

En cualquier caso, ya en un contexto histórico distinto, en el que la evolución del modelo regio había saltado por encima de esas exigencias de consenso para afirmarse una marcada tendencia absolutizadora, tal como sucedió durante la época de los Austrias, sería posible la concepción de un modelo de palacio real en el que podía percibirse presente a la vez la dimensión política y religiosa, y cuya exclusividad regia no chirriaba con las demandas de pacto político de otros tiempos. Es más, en ese contexto más tardío se hacía particularmente necesaria la manifestación de un palacio real en el que quedaba incluida una espacialidad sagrada coherente con la explicitación de un poder real cada vez más controlador de la dimensión eclesial y religiosa del reino. Pero esta última perspectiva nos llevaría a un marco histórico que respondería a criterios conceptuales y mentales no del todo coincidentes con el que aquí ha sido objeto de atención. 